Manuscript Number: JCLEPRO-D-18-12770R2

Title: Characterisation and partition of valuable metals from WEEE in weathered municipal solid waste incineration bottom ash, with a view to recovering

Article Type: Original article

Keywords: municipal solid waste incineration; weathered bottom ash; valuable metals; sequential extraction; total acid digestion; metal recovery.

Corresponding Author: Dr. Josep Maria Ma. Chimenos, Ph.D.

Corresponding Author's Institution: University of Barcelona

First Author: Susanna Pérez-Martínez

Order of Authors: Susanna Pérez-Martínez; Jessica Giro-Paloma; Àlex Maldonado-Alameda; Joan Formosa; Ignasi Queralt; Josep Maria Ma. Chimenos, Ph.D.

Abstract: As the demand for critical and valuable metals increases due to industrial developments, especially in electronics and high-technology industries, the search for novel and sustainable sources grows in significance. Incinerated municipal solid waste (MSW) is a potential source of valuable metals, since a lot of waste from electrical and electronic equipment (WEEE) is not recycled properly and are is managed together with the refuse fraction of MSW, which is often landfilled or incinerated. Bottom Ash (BA) is the main by-product of incinerated MSW, which has been characterized to assess the potential recovery of valuable metals. The determination of the total amount of valuable metals (Ag, Al, $\mathrm{Au}, \mathrm{Be}, \mathrm{Co}, \mathrm{Cu}, \mathrm{Ga}, \mathrm{Ge}$, In, Ir, Li, $\mathrm{Ni}, \mathrm{Pd}, \mathrm{Pt}, \mathrm{Sb}, \mathrm{Ta}$, and $\mathrm{W}$ ) in seasonal samples of weather bottom ash (WBA) was performed by a total acid digestion followed by a chemical analysis. Besides, a sequential extraction procedure (SEP) is conducted to define their partition. The characterisation has shown that the content of valuable metals in the incineration WBA, which was highest in the 0 - $2 \mathrm{~mm}$ fraction was much lower than in concentrated ores commonly used as primary sources. Moreover, the SEP showed little potential for the valorisation of most of the metals, as they are embedded in or bound to a silicic matrix or sintered metal oxides, and so their extraction requires strong-acid digestion or a highly oxidizing environment. This work contributes to the use of residual sources as secondary resources and to the correct management of the end-of-life electrical and electronic equipment. 


\section{Manuscript: JCLEPRO-D-18-12770.}

Title: Characterisation and partition of valuable metals from WEEE in weathered municipal solid waste incineration bottom ash, with a view to recovering

Authors: S. Pérez-Martínez, J. Giro-Paloma, A. Maldonado-Alameda, J. Formosa, I. Queralt, J.M. Chimenos

We thank the Editor for his valued comments.

1. Kindly avoid having one heading after another heading without any text in between as shown in Section 3.

Done.

2. Kindly proof read the document for grammatical errors. An example is in the first line of the abstract

An English advisor from the University of Barcelona has reviewed the manuscript.

3. Kindly highlight in the abstract, introduction and conclusion how the work proposed contributes towards the promotion or adoption of cleaner production or the improvement in environmental impact.

Done

Sincerely,

JM Chimenos 


\section{Characterisation and partition of valuable metals from WEEE in} weathered municipal solid waste incineration bottom ash, with a view to recovering.

S. Pérez-Martínez ${ }^{\mathrm{a}}$, J. Giro-Paloma ${ }^{\mathrm{a}}$, A. Maldonado-Alameda ${ }^{\mathrm{a}}$, J. Formosa ${ }^{\mathrm{a}}$, I. Queralt ${ }^{\mathrm{b}}$, J.M. Chimenos ${ }^{\mathrm{a}, *}$

${ }^{\text {a }}$ Departament de Ciència de Materials i Química Física, Facultat de Química, Universitat de Barcelona, Martí i Franquès, 1, E-08028 Barcelona, Spain.

${ }^{\mathrm{b}}$ Institut de Diagnosi Ambiental i Estudis de l'Aigua, IDAEA-CSIC, Jordi Girona 18-26, E-08034 Barcelona, Spain.

\footnotetext{
"Corresponding author: chimenos@ub.edu
} 


\section{Highlights}

WEEE are not recycled properly and are managed with the refuse fraction of MSW MSWI bottom ash is a potential source of valuable metals coming from WEEE MSWI bottom ash has been characterized to evaluate the recovery of valuable metals Valuable metals are mainly in fine fractions with lower contents than mineral sources Valuable metals are embedded in Si-matrix and require severe condition for extraction 
Characterisation and partition of valuable metals from WEEE in weathered municipal solid waste incineration bottom ash, with a view to recovering.

S. Pérez-Martínez ${ }^{\mathrm{a}}$, J. Giro-Paloma ${ }^{\mathrm{a}}$, A. Maldonado-Alameda ${ }^{\mathrm{a}}$, J. Formosa ${ }^{\mathrm{a}}$, I. Queralt ${ }^{\mathrm{b}}$, J.M. Chimenos $^{\mathrm{a}, *}$

${ }^{a}$ Departament de Ciència de Materials i Química Física, Facultat de Química, Universitat de Barcelona, Martí i Franquès, 1, E-08028 Barcelona, Spain.

${ }^{\mathrm{b}}$ Institut de Diagnosi Ambiental i Estudis de l'Aigua, IDAEA-CSIC, Jordi Girona 18-26, E08034 Barcelona, Spain.

\footnotetext{
*Corresponding author: chimenos@ub.edu
} 


\section{Abstract}

As the demand for critical and valuable metals increases due to industrial developments, especially in electronics and high-technology industries, the search for novel and sustainable sources grows in significance. Incinerated municipal solid waste (MSW) is a potential source of valuable metals, since a lot of waste from electrical and electronic equipment (WEEE) is not recycled properly and are is managed together with the refuse fraction of MSW, which is often landfilled or incinerated. Bottom Ash (BA) is the main by-product of incinerated MSW, which has been characterized to assess the potential recovery of valuable metals. The determination of the total amount of valuable metals $(\mathrm{Ag}, \mathrm{Al}, \mathrm{Au}, \mathrm{Be}, \mathrm{Co}, \mathrm{Cu}, \mathrm{Ga}, \mathrm{Ge}, \mathrm{In}, \mathrm{Ir}$, Li, Ni, Pd, Pt, Sb, Ta, and W) in seasonal samples of weather bottom ash (WBA) was performed by a total acid digestion followed by a chemical analysis. Besides, a sequential extraction procedure (SEP) is conducted to define their partition. The characterisation has shown that the content of valuable metals in the incineration WBA, which was highest in the 0 - $2 \mathrm{~mm}$ fraction was much lower than in concentrated ores commonly used as primary sources. Moreover, the SEP showed little potential for the valorisation of most of the metals, as they are embedded in or bound to a silicic matrix or sintered metal oxides, and so their extraction requires strong-acid digestion or a highly oxidizing environment. This work contributes to the use of residual sources as secondary resources and to the correct management of the end-of-life electrical and electronic equipment.

Keywords: municipal solid waste incineration, weathered bottom ash, valuable metals, sequential extraction, total acid digestion, metal recovery. 


\section{Introduction}

Incineration has become the preferred treatment of municipal solid waste (MSW) in Europe, as the most feasible alternative to landfilling, since it allows both waste volume and weight to be reduced (Bontempi et al., 2010; Puma et al., 2013). Bottom ash (BA) is the most significant by-product from MSW incineration: as it accounts for $85-95 \%$ of the solid product resulting from combustion and it is considered a slag and granular material (Izquierdo et al., 2002), which is catalogued as a non-hazardous material (del Valle-Zermeño et al., 2017a). However, BA is heterogeneous material whose composition and chemical characterization is a function of particle size (Chimenos et al., 2003). Overall, BA is mainly composed of silicon, calcium, iron, aluminium, and sodium; and it can be revalorized as a secondary building material after being stabilized through a weathering process (del Valle-Zermeño et al., 2017b, 2014, 2013). Nevertheless, it also contains a considerable amount of heavy metals and therefore in some countries it is disposed of in landfills (Wielgosiński et al., 2014).

Currently, waste from electrical and electronic equipment (WEEE) is one of the fastest growing categories of waste streams in the EU, with a growth rate of 3\%-5\% per year; much higher than the rate for MSW (Eurostat, 2018). However, not all of the electrical and electronic equipment used goes through the official WEEE treatment system. While most large household appliances are collected separately and managed appropriately, a high percentage of smaller household appliances, telecommunications equipment, lighting apparatus, and electrical and electronic tools still find their way into the refuse (undifferentiated household) fraction of MSW, which is often incinerated or disposed of in landfills.

Modern WEEE may contain more than 60 different elements; many of them are valuable, some are hazardous and others are both (Kaya, 2016; Schluep et al., 2009; Zhang and Xu, 
2016). It is mainly composed of metals ( $\sim 60 \%$ weight), followed by plastics ( $15 \%$ weight), and both CRTs and LCD screens (12\% weight). For instance, in the specific case of mobile phones (of which metals represent some $23 \%$ of the weight), there can be 40 elemental metals: basic metals, such as $\mathrm{Cu}, \mathrm{Fe}$ or $\mathrm{Sn}$; special metals, such as $\mathrm{Co}, \mathrm{Li}, \mathrm{Be}$, Ir or $\mathrm{Sb}$; precious metals, such as $\mathrm{Ag}, \mathrm{Au}$ or Pd; and also rare earth elements (REEs). In this regard, although WEEE only accounts for a small percentage of MSW, the variety and proportion of valuable metals in it is far higher than in other refuse waste fractions ( $\mathrm{Li}$ and $\mathrm{Xu}, 2015)$. Most of the metals come from non-renewable resources; with some already having seen more than $60 \%$ of total reserves in the earth's crust mined. According to the European Commission, some of these metals present a higher risk of future shortage, this is due to their supply being highly dependent on imports from only a few countries which are sometimes politically or economically unstable, and due to their considerable importance for specific economic sectors (Commission of the European Communities, 2008). Moreover, compared with the production of primary metals, recycling metal resources from WEEE has significant advantages, such as producing less secondary waste and lower energy consumption. Additional studies are therefore needed on the fate of metals throughout the entire WEEE recycling and treatment system, including the treatment of residues containing WEEE.

During the incineration of MSW, the metals contained in WEEE are concentrated into one of the forms of waste generated by the combustion process: BA or fly ash. Considering the diversity and complexity of the physical and chemical phenomena involved in the transformation, the behaviour of metals depends on their tendency to react and to change their aggregate state (Zhang et al., 2012). For instance, $\mathrm{Hg}$ and $\mathrm{Cd}$ are two volatile metals that can be considered negligible in $\mathrm{BA}$; meanwhile metals such as $\mathrm{Fe}, \mathrm{Cu}, \mathrm{Cr}, \mathrm{Co}, \mathrm{Ni}$ and other volatile metals such as $\mathrm{Pb}$ and $\mathrm{Zn}$ mostly remain in $\mathrm{BA}$ (Belevi and Moench, 2000; Jung et 
al., 2004; Yao et al., 2010; Zhang et al., 2008, 2012). Similarly, metals with higher densities,

Although ferrous and non-ferrous metals are frequently removed from BA by means of electromagnets and Eddy current separators, respectively, the processes are mostly effective in the size fraction containing particles larger than 5-8 mm (Biganzoli et al., 2014; del ValleZermeño et al., 2017b). For instance, $\mathrm{Al}$ recovery has long been used because it is easy to reuse and the process allows up to $95 \%$ of the energy required for primary production to be saved (Hu et al., 2011; Zhou et al., 2006). However, 90\% of total Al (metal and $\mathrm{Al}$ compounds) is found in the fraction smaller than $1 \mathrm{~mm}$ and it is regarded to come mainly from light packaging and $\mathrm{Al}$ foils (Biganzoli et al., 2013). Just as for $\mathrm{Al}$, it is expected that some valuable metals also remain in $\mathrm{BA}$, and that many of these come from incinerated WEEE (del Valle-Zermeño et al., 2017b). Nevertheless, given the highly heterogeneous distribution of the materials in BA (Loginova et al., 2019), the contents of one specific metal may differ as a function of particle size. Therefore, depending on their nature and composition, the metals contained in certain size fractions potentially has recycling value.

Spain acquires and disposes of a large amount of electrical and electronic equipment (EEE) every year. In 2016, a total of $626 \mathrm{kT}$ of new electrical and electronic goods were placed on the market (according to the Spanish Ministry of Agriculture, Fisheries, Food and the Environment), while only $313 \mathrm{kT}$ (3.8 kg per inhabitant) of WEEE was recovered or reused in the same period (Eurostat, 2018). So, it can be assumed that around 50\% of WEEE went into the refuse fraction of MSW. Meanwhile, MSW incineration has increased in Spain in recent years, and there are currently 10 waste-to-energy (WtE) plants. Four of these WtE plants are located in Catalonia (north-east Spain), an autonomous region where more than $17 \%$ of MSW collected was incinerated in 2016 and 134 kT of BA was produced (AEVERSU, 2018). Reuse of BA as a secondary raw material is regulated by the Standards of the Catalonian authorities. 
However, for its proper reutilization, after removing ferrous and non-ferrous metals, BA must be stabilized through a weathering process (of some 2-3 months) in order to obtain weathered bottom ash (WBA).

In accordance with this situation, the main objective of this research is to assess the possibility of recovering valuable metals contained in WBA generated from MSW incineration, depending on the fractions of different particle sizes and based on their content and chemical nature. Along with the commonly studied $\mathrm{Al}, \mathrm{Ni}$ and $\mathrm{Cu}$, other valuable metals usually present in WEEE are also determined. In addition to total contents using total acid digestion, a four-step sequential extraction procedure for each particle-size fraction is also performed, in order to determine the partitioning of valuable metals and their availability to an extraction process. Finally, an important objective of this research is to define whether it is possible to recover the valuable metals contained in WBA from WEEE, or whether different management options would better facilitate their recovery.

\section{Materials and methods}

For the present research, WBA was collected from a WtE plant located in Tarragona (NE Spain). The incineration plant feed stream mainly consisted of household rubbish, with a small input from commercial sources. Approximately $32 \mathrm{kT}$ of fresh BA is produced in the incineration plant and further treated in a conditioned/revalorization process for the recovery of ferrous and non-ferrous metals, and to remove lightweight materials. After being conditioned, the BA is stock-piled in the open for at least three months to ensure immobilization of heavy metals by weathering. In order to determine possible seasonal changes in the composition of the MSW, three sampling campaigns were carried out, during the months of February, July, and October. For each sampling period, around $40 \mathrm{~kg}$ of WBA was taken from various stockpiles, homogenized and stored in a $30 \mathrm{~L}$ plastic container. 
The particle size distribution (PSD) of each seasonal sample (Fig. 1a) was determined using a procedure employed in previous research (del Valle-Zermeño et al., 2017b). This consisted of sieving the WBA (dried overnight at $105^{\circ} \mathrm{C}$ ) with openings of 2, 4, 8 and $16 \mathrm{~mm}$ (EN 933-2). As can be seen in Fig. 1a, PSD analysis showed similar profiles for all seasons and the small differences could be explained by the consumption of different seasonal materials.

After sieving, in order to facilitate chemical characterization, each fraction (Entire, >16, 8-16, 4-8, 2-4 and 0-2 mm) was initially crushed in a jaw crusher and subsequently milled in a vibratory disc mill, using a hardened steel grinding set. Milling continued until the whole sample passed through an $80 \mu \mathrm{m}$ mesh and produced a fine homogeneous powder. Likewise, for each size fraction, metal particles larger than $500 \mu \mathrm{m}$, plastically deformed by impacts during crushing and milling, were removed manually and quantified using a magnet and a magnifying glass, and kept separately for further chemical analysis (Fig. 1b). The metal content increased in the finer fractions $(<8 \mathrm{~mm})$ where the metal removal (electromagnetic and Eddy currents) devices were not operative (del Valle-Zermeño et al., 2017b).

The chemical composition of the major elements in the non-metallic fraction of each WBA size fraction was determined by X-ray fluorescence spectroscopy (XRF) using an S2 Ranger spectrometer (Bruker/AXS GmbH, Germany). For each size fraction, the contents of major elements were similar regardless of the season. Table 1 shows the average content of major elements according to WBA particle size. As reported elsewhere (del Valle-Zermeño et al., 2013), Si, Ca, and Al were the most abundant constituents, which mainly come from sodalime glass and other natural or synthetic ceramic materials. Accordingly, the content of $\mathrm{Si}$ is greater in the size fractions where soda-lime glass is also more common; while the $\mathrm{Ca}$ and $\mathrm{Al}$ contents are higher when the ceramics content is also high (del Valle-Zermeño et al., 2017b). 
The mineral and crystalline phases in the WBA (see Table 3) were identified by powder X-ray diffraction analysis (XRD) using an Expert diffractometer (Panalytical, Netherlands). It should be emphasized that while some mineralogical phases usually considered in the literature were identified (Chimenos et al., 1999; Gonzalez et al., 2017; Xia et al., 2017), the initial sample presented an amorphous phase because of its glass content, which is the main component of the WBA (del Valle-Zermeño et al., 2017b), and therefore could not be identified by XRD. However, this packaging glass (primary glass) is one of the precursors of secondary glass, which is newly formed during the combustion process at high temperatures.

\subsection{Total acid digestion}

Total acid digestion of all the sub-samples studied (metal and non-metal fractions) was carried out to quantify the total contents of valuable metals contained in WBA, as a function of particle size. Around $0.5 \mathrm{~g}$ of dry powdered ash was accurately digested at $90{ }^{\circ} \mathrm{C}$ in Teflon ${ }^{\circledR}$ closed-reactors using a sequence of mineral acids $\left(\mathrm{HNO}_{3} / \mathrm{HF}, \mathrm{HClO}_{4} / \mathrm{HNO}_{3} / \mathrm{H}_{2} \mathrm{O}_{2}\right)$. The resulting leachates were diluted to $100 \mathrm{~mL}$ with $2 \% \mathrm{HNO}_{3}$ and stored in polyethylene tubes at $4{ }^{\circ} \mathrm{C}$ until analysis using inductively coupled plasma mass spectrometry (ICP-MS).

From all the valuable metals contained in WEEE, after prior semi-quantitative analysis, the list of determined metals ( $\mathrm{Ag}, \mathrm{Al}, \mathrm{Au}, \mathrm{Be}, \mathrm{Co}, \mathrm{Cu}, \mathrm{Ga}, \mathrm{Ge}, \mathrm{In}, \mathrm{Ir}, \mathrm{Li}, \mathrm{Ni}, \mathrm{Pd}, \mathrm{Pt}, \mathrm{Sb}$, Ta, and W) differs from those critical metals established by the European Community for reasons. Firstly, some critical metals, such as the REEs, are in extremely low concentrations in WBA (Allegrini et al., 2014; Morf et al., 2013), and their concentrations in the leachates would be below the ICP-MS limit of detection. Secondly, there are some valuable metals (e.g., Al, $\mathrm{Cu}$ and $\mathrm{Ni}$ ) which are not considered critical but their abundance in the sample makes their recovery economically feasible (Gonzalez et al., 2017; Morf et al., 2013). Finally, there are 
also other valuable metals, such as $\mathrm{Ag}$ and $\mathrm{Au}$, whose high prices make their recovery feasible, although their contents are not very high.

\subsection{Sequential Extraction}

An SEP was performed to determine the partition of valuable metals contained in WBA. The principle of the sequential extraction was a solid sample treatment in several consecutive steps with different solutions, increasing the chemical attack intensity. Each step leads to a solution (separated by centrifugation) and also a residual solid, which is then subjected to the next extraction solution. A modified BCR sequential extraction procedure defined by Rauret et al. (1999) was applied to all the WBA sub-samples. All the reagents were of analytical grade and the extracting solutions were prepared immediately before performing the leaching. The leachates obtained were analysed using ICP-MS and the metals quantified were the same as those analysed in the total acid digestion (Section 2.1.). Due to the similarities between the three seasonal WBA samples, the SEP was only conducted on the July sample: it may be assumed that the main results and conclusions can be extrapolated to the other two samples.

In accordance with the proposed SEP, five operational fractions were established:

Exchangeable fraction (Step 1): $1 \mathrm{~g}$ of the sample was extracted by shaking for $16 \mathrm{~h}$ (overnight) at room temperature with $40 \mathrm{~mL}$ of ultrapure water.

Carbonate fraction (Step 2): the residue from the previous step (Residue 1) was extracted with $40 \mathrm{~mL}$ of acetic acid $0.1 \mathrm{M}(\mathrm{pH} \simeq 2.9)$, by shaking for $16 \mathrm{~h}$ (overnight).

Hydroxide fraction (Step 3): the residue from the previous step (Residue 2) was extracted with $40 \mathrm{~mL}$ of a solution of hydroxylamine hydrochloride $0.5 \mathrm{M}$ acidified with $2.5 \% \mathrm{HNO}_{3}$ $2.0 \mathrm{M}(\mathrm{pH} \simeq 1.3)$, by shaking for $16 \mathrm{~h}$ (overnight). 
Organic matter fraction (Step 4): the residue from the previous step (Residue 3) was extracted with $10 \mathrm{~mL}$ of $30 \%$ hydrogen peroxide adjusted to $\mathrm{pH}=2-3$ with $\mathrm{HNO}_{3}$, by shaking for $1 \mathrm{~h}$ at room temperature, while covered with a watch glass to avoid excessive evaporation. Then, the uncovered solution was shaken at $85 \pm 2{ }^{\circ} \mathrm{C}$ in a water bath for an hour. Then, a further $10 \mathrm{~mL}$ of hydrogen peroxide $\left(30 \%, \mathrm{pH}=2-3\right.$ with $\mathrm{HNO}_{3}$ ) was added and the covered sample was heated to $85 \pm 2{ }^{\circ} \mathrm{C}$ in a water bath and maintained in it for a total of an hour. Finally, the liquid volume was reduced to $1 \mathrm{~mL}$ by heating; $50 \mathrm{~mL}$ of ammonium acetate $1 \mathrm{M}$ was added; and the sample was extracted for $16 \mathrm{~h}$ (overnight) by shaking.

Residual fraction (Step 5): the residue of the previous step (Residue 4) was digested following the procedure carried out in the total acid digestion (Section 2.1).

\section{Results and Discussion}

In this section, the results of the total acid digestion and the SEP will be discussed. The former involves acid digestion with $\mathrm{HNO}_{3}$ of each sieved fraction of WBA to elucidate its chemical composition. The latter allows us to determine the fractionation and mobility of valuable metals analysed in each extraction environment, which is related to the metal chemical speciation.

\subsection{Total Acid Digestion}

Table 2 shows the results of the total acid digestion for all the seasonal WBA samples studied. A comparison has been established between the results of each WBA fraction. As can be observed, for each particle-size fraction, the content of the metals analysed is highly similar for the three seasonal samples (February, July, and October). However, in cases the metal content in a specific fraction is unexpectedly high, (e.g., Co in the $8-4 \mathrm{~mm}$ size fraction of WBA samples collected in July, Table 2). This can be explained by the heterogeneous nature of the samples, especially in the metal fraction of each particle size, even though all the 
samples were carefully quartered. Moreover, the heterogeneity of these metal fractions can also explain the unusually large error bars in a few cases (see Figs. 2 and 3). However, for most of the valuable metals analysed, taking into account the PSD and the ratio of each size fraction (Fig. 1a), the sum of the contents of each fraction is very similar to the metal content determined for the entire sample. That is, the samples are representative and properly quartered.

It should be noted that the highest metal contents in WBA corresponded to $\mathrm{Al}$ (around 75 $\mathrm{g} \cdot \mathrm{kg}^{-1}$ ); while $\mathrm{Cu}$ and $\mathrm{Ni}$ also have considerable concentrations (around $2 \mathrm{~g} \cdot \mathrm{kg}^{-1}$ and $0.1 \mathrm{~g} \cdot \mathrm{kg}^{-}$ ${ }^{1}$, respectively). Although these contents might appear to indicate abundance, they are far below the typical levels concentration in ores commonly used as primary resources (Allegrini et al., 2014). Only $\mathrm{Cu}$, in some size fractions, is just two or three times less concentrated than the content of primary ores. The highest content of all, with an occasional exception, was found in the finer fractions $(<8 \mathrm{~mm})$, where non-ferrous metal recovery devices (i.e., Eddy current separators) cannot be use (del Valle-Zermeño et al., 2017b) or are not efficient enough. While $\mathrm{Cu}$ and $\mathrm{Ni}$ are mainly present as base metals or as alloying elements (e.g. wrought $\mathrm{Al}$ alloys or austenitic stainless steels), $\mathrm{Al}$ is also present in a large range of natural and synthetic ceramics like clays, soda-lime glass, tiles and aluminosilicate-based ceramics.

According to total content, a second group of metals ranged from 10 to $100 \mathrm{mg} \cdot \mathrm{kg}^{-1}$, including $\mathrm{Sb}, \mathrm{Li}, \mathrm{Co}$, and $\mathrm{Ga}$; although these contents are again much lower than those found in the concentrated minerals used as primary resources for beneficiation (Allegrini et al., 2014). The amount of $\mathrm{Li}$ determined might come mainly from rechargeable and nonrechargeable batteries; although to a lesser extent it is also used in some ceramics and glass. $\mathrm{Sb}$ is used as an alloying element (mainly $\mathrm{Pb}$ alloys), but also in electric and electronic industries for cable sheathing to make semiconductor devices or in TV screens, as well as being a flame retardant for many polymeric materials. Co is found in Li-ion batteries, as well 
as in some non-ferrous alloys to make powerful magnets; meanwhile Ga is used mainly in the electronics industry in semiconductor devices.

$\mathrm{Ag}, \mathrm{Be}, \mathrm{Pd}$, and $\mathrm{W}$ were found in contents ranging between 1 and $10 \mathrm{mg} \cdot \mathrm{kg}^{-1} . \mathrm{Ag}, \mathrm{Pd}$, and $\mathrm{Be}$ are all widely used in EEE; they can be found in cable and high-definition televisions, electrical contacts, connectors, and screens in cell phones and computers, for example. While W mainly comes from incandescent light bulbs, W-alloyed steel is used for tools, and even from the balls of ballpoint pens (Morf et al., 2013).

The lowest concentrations of metals were found for $\mathrm{Au}$, In, and Ta; whereas Ir, Pt, and Ge were analysed, but most of the size fractions or replicates analysed presented values below the ICP-MS limit of detection ( $\mathrm{Ir}<0.025 \mathrm{mg} \cdot \mathrm{kg}^{-1}$; Pt $<0.25 \mathrm{mg} \cdot \mathrm{kg}^{-1} ; \mathrm{Ge}<0.25 \mathrm{mg} \cdot \mathrm{kg}^{-1}$ ). In is used in semiconductors and in flat-screen TVs and computer screens; Au is present in most connectors in EEE; and Ta is found in semiconductors and crystals for infrared instruments.

Although the concentrations of the metals studied are relatively low, if considering valorisation, and lower than concentrated ores used as primary resources, it must be considered that the production of WBA in this conditioning plant is about 2,400 tonnes per month. This leads to approximately $86 \mathrm{~kg}$ per year of $\mathrm{Ag}$ and $29 \mathrm{~kg}$ per year of $\mathrm{Au}$, as examples. Moreover, taking into account the PSD and the greater content of metals in the fine fractions, it is possible to increase recovery performance for some valuable metals by treating only the finer fractions (e.g. $<8 \mathrm{~mm}$, which represents around $70 \%$ of total WBA).

\subsection{Sequential Extraction Procedure}

The potential extraction depends on different factors including: $\mathrm{pH}$, the mineralogical phases present, the amount of organic matter, salt concentrations, complexation agents, and the presence of $\mathrm{Fe} / \mathrm{Mn} / \mathrm{Al}$ oxides or hydroxides (Hursthouse, 2001). 
Table 3 shows the major mineral phases for the WBA sample collected in July, as well as the

It should be noted again that the diffraction patterns obtained for each residue show an important presence of amorphous phases, most probably due to the large content of vitreous phases. The packaging (primary) glass which is present in large quantities in the MSW acts as one of the precursors of secondary glass, which is formed at high temperatures during the combustion process and could embed other materials and mineral phases. XRD analysis of the SEP Residues 1 - 4 corroborates the solving of some mineralogical phases from one step to the next. Most of the mineralogical phases were dissolved after carrying out Step 3 (oxidizing environment), with the notable exception of quartz and these phases of the silicic matrix, which were still present in Residue 4. It is worth noting the presence of ammonium chloride in Residue 3, as its origin is the extraction reagent used in Step 3 (hydroxylamine hydrochloride), which remains in the residue after the extraction procedure. In contrast, other crystalline phases, such as anhydrite and hydrocalumite, which are present in the initial WBA sample, disappear after carrying out the first step (aqueous environment).

The chemical characterization of each of the residual fractions obtained in the SEP, determined by XRF (Table 4), corroborates the solving of some mineralogical phases during the different extraction steps. As can be seen, the $\mathrm{SiO}_{2}$ and $\mathrm{Fe}_{2} \mathrm{O}_{3}$ contents of the Residues increase as the extractive steps progress; while the contents of $\mathrm{Al}_{2} \mathrm{O}_{3}$ and $\mathrm{CaO}$ decrease. This variation in the content of silica, alumina, hematite or lime can be better appreciated by considering the $\mathrm{SiO}_{2} / \mathrm{Al}_{2} \mathrm{O}_{3}, \mathrm{SiO}_{2} / \mathrm{CaO}, \mathrm{Fe}_{2} \mathrm{O}_{3} / \mathrm{CaO}$ or $\mathrm{Al}_{2} \mathrm{O}_{3} / \mathrm{CaO}$ ratios. All of these increase significantly, due to the greater dissolution of the mineralogical phases containing calcium and, to a lesser extent, aluminium; while the particles with a siliceous matrix or iron (hydr)oxides remain unchanged and are concentrated in the final solid phase of the extractive process (Residue 4). At this point, it must be taken into account that the presence of iron 
should not only be attributed to crystalline phases, but also to the presence of amorphous $\mathrm{Fe}$ (hydr)oxides, as determined in BA (Dijkstra et al., 2006). Highlight again the high chloride content of Residue 3, from the hydroxylamine hydrochloride used as the reagent in Step 3, which remains in the residue after the extraction.

The concentrations $\left(\mathrm{mg} \cdot \mathrm{kg}^{-1}\right)$ of valuable metals extracted in each step of the SEP are plotted in Figs. 2 and 3. A comparison between the total amount of each metal extracted during the SEP and the value obtained for the total acid digestion is also shown with the aim of evaluating the effectiveness of the SEP compared to the total acid digestion. Theoretically, total digestion metal concentrations should be equal to the sum of the individual SEP fractions for each metal.

It is noticeable from Figs. 2 and 3 that, with some possible exceptions, the correlation between extractability using the total digestion approach and the sum of the individual fractions of metals from the SEP is not excellent. This is more evident in some particle-size fractions of some of the metals analysed. The main reasons for this may have to do with the heterogeneity and aggregation state of the metal fractions analysed for each particle size; although other authors discuss other reasons, including the re-adsorption and re-distribution of metals among phases during the extraction process, and incomplete dissolution of the target phase during extraction (Gómez-Ariza et al., 1999). In addition, new solid phases may be precipitated from the leachate, the reagents may not be sufficiently selective for the target phase, and the extraction may be inefficient and hence incomplete (Bacon and Davidson, 2008).

However, for almost all the valuable metals analysed, it should be highlighted that the relation between the fractions established in the SEP (partition) was quite similar for all the size fractions. That is, although the content of a metal is different for each size fraction, its 
distribution between the five operational fractions of the SEP did not depend on the WBA particle size. In this regard, it was found that $\mathrm{Au}, \mathrm{Be}, \mathrm{Li}, \mathrm{Ni}, \mathrm{Sb}, \mathrm{Ta}$, and $\mathrm{W}$ were mainly contained in Residue 4 and were released in Step 5, requiring strong-acid digestion to extract them. That is, these valuable metals would be mostly bound to or embedded in silicate minerals (e.g. a glass matrix) or metal oxides sintered at high temperatures (e.g. iron oxides), which prevent the reagents from gaining access to the metals.

For Ag, Al, Ga, In, and Pd, the content extracted in Steps 4 and 5 were quite similar. Thus, it is to be expected that these metals would be both embedded in a silicic structure (e.g. a glass matrix) and bound to oxidizable matter. Ga was also extracted in Step 1 (water environment); therefore it is partly adsorbed on the surface of solid particles and is easily released. Meanwhile, $\mathrm{Cu}$ was mainly in its oxidized chemical form, as it was extracted in quantity in Step 3; and Co was mainly released during Step 2, which means that it might be bound to carbonates and released in the acid environment.

\section{Conclusions}

Although a high percentage of WEEE goes to the refuse fraction of MSW, which is increasingly managed in $\mathrm{WtE}$ plants, it has been determined the content of valuable metals in WBA, which is much lower than the concentration of these metals in the concentrated ores commonly used as primary sources. Most critical metals, such as REEs, are found in very low concentrations, even below the limits of detection the analysis techniques used. Accordingly, only some valuable metals (Ag, Al, $\mathrm{Au}, \mathrm{Be}, \mathrm{Co}, \mathrm{Cu}, \mathrm{Ga}, \mathrm{Ge}$, In, Ir, Li, Ni, Pd, Pt, Sb, Ta, and W), due to their higher contents, high market price or industrial interest, have been estimated to evaluate the feasibility of recovering them from WBA generated during the incineration of MSW. 
The content of these valuable metals increases as the particle size decreases, with the highest in the $0-2 \mathrm{~mm}$ fraction, although this is still well below the content of naturally occurring concentrated ores. According to bibliographic data, of all the valuable metals studied, only the concentration of copper was within a factor of two or three of the contents of concentrated minerals. However, the difference in content between the different size fractions is not large enough to make separation by particle sizes alone a feasible option for concentrating the valuable metals enough for their recovery to be economically viable.

The sequential extraction performed shows that most of the metals analysed are mainly extracted from the Residue 4, where strong-acid digestion is required to extract them. Accordingly, most of these valuable metals can be assumed to be embedded in secondary glass formed during the combustion process, linked to a silicic matrix, or to form part of the structure of other metal oxides, such as iron oxides sintered at elevated temperatures. This makes recovery even more difficult, given that more severe conditions are required.

To extend and complete this study, similar research should be performed on the non-ferrous fraction of BA, recovered in the conditioning plant by Eddy current devices. This would determine if these valuable metals are more concentrated in this fraction and their extraction easier.

Despite the low concentrations of valuable metals and the difficulty in their extraction from $\mathrm{BA}$, it must be noted that due to a large amounts of BA generated each year, considerable amounts of valuable metals are not recovered and end up in landfills or as secondary building materials. Therefore, the recovery of these valuable metals should be based on a more effective policy of WEEE management, i.e. separate collection and proper management, rather than difficult and expensive extraction processes of the MSWI weathered bottom ash. 
Proper management of WEEE prior to incineration of RSU will contribute to more sustainable uses of resources.

\section{Acknowledgements}

This work was partially funded by the Spanish Government (BIA2017-83912-C2-1-R). The authors would like to thank the companies SIRUSA and VECSA for their financial support and for providing access to sampling sites. The authors would like to thank the regional Catalan authorities for the accreditation of the quality of the research group: DIOPMA (2017 SGR 118). Mr. Maldonado-Alameda thanks the Catalan authorities for his postgraduate grant (FI-DGR 2017). 


\section{References}

AEVERSU., 2018. Asociación de Empresas de Valorización Energética de Residuos Urbanos [WWW Document]. URL http://Www.aeversu.org

Allegrini, E., Maresca, A., Olsson, M.E., Holtze, M.S., Boldrin, A., Astrup, T.F., 2014. Quantification of the resource recovery potential of municipal solid waste incineration bottom ashes. Waste Manag. 34. doi:10.1016/j.wasman.2014.05.003

Bacon, J.R., Davidson, C.M., 2008. Is there a future for sequential chemical extraction? Analyst 133, 25-46. doi:10.1039/B711896A

Belevi, H., Moench, H., 2000. Factors Determining the Element Behavior in Municipal Solid Waste Incinerators. 1. Field Studies. Environ. Sci. Technol. 34, 2501-2506. doi:10.1021/es991078m

Biganzoli, L., Grosso, M., Forte, F., 2014. Aluminium mass balance in waste incineration and recovery potential from the bottom ash: A case study. Waste and Biomass Valorization $5,139-145$.

Biganzoli, L., Ilyas, A., Praagh, M. V, Persson, K.M., Grosso, M., 2013. Aluminium recovery vs. hydrogen production as resource recovery options for fine MSWI bottom ash fraction. Waste Manag. 33, 1174-1181.

Bontempi, E., Zacco, A., Borgese, L., Gianoncelli, A., Ardesi, R., Depero, L.E., 2010. A new method for municipal solid waste incinerator (MSWI) fly ash inertization, based on colloidal silica. J. Environ. Monit. 12, 2093-2099.

Chimenos, J.., Segarra, M., Fernández, M.., Espiell, F., 1999. Characterization of the bottom ash in municipal solid waste incinerator. J. Hazard. Mater. 64, 211-222. 


$$
\text { doi:10.1016/S0304-3894(98)00246-5 }
$$

Chimenos, J.M., Fernández, A.I., Miralles, L., Segarra, M., Espiell, F., 2003. Short-term natural weathering of MSWI bottom ash as a function of particle size. Waste Manag. 23, 887-895. doi:S0956- 053X(03)00074-6

Commission of the European Communities, 2008. The raw materials initiative - meeting our critical needs for growth and jobs in Europe 14.

del Valle-Zermeño, R., Chimenos, J.M., Giró-Paloma, J., Formosa, J., 2014. Use of weathered and fresh bottom ash mix layers as a subbase in road constructions: Environmental behavior enhancement by means of a retaining barrier. Chemosphere 117, 402-409. doi:10.1016/j.chemosphere.2014.07.095

del Valle-Zermeño, R., Formosa, J., Chimenos, J.M., Martínez, M., Fernández, A.I., 2013. Aggregate material formulated with MSWI bottom ash and APC fly ash for use as secondary building material. Waste Manag. 33, 621-7. doi:10.1016/j.wasman.2012.09.015

del Valle-Zermeño, R., Giro-Paloma, J., Formosa, J., Chimenos, J.M., 2017a. APC Fly Ash Recycling: Development of a Granular Material from Laboratory to a Pilot Scale. Waste and Biomass Valorization 8. doi:10.1007/s12649-016-9644-8

del Valle-Zermeño, R., Gómez-Manrique, J., Giro-Paloma, J., Formosa, J., Chimenos, J.M., 2017b. Material characterization of the MSWI bottom ash as a function of particle size. Effects of glass recycling over time. Sci. Total Environ. 581-582, 897-905. doi:10.1016/J.SCITOTENV.2017.01.047

Dijkstra, J.J., Van Der Sloot, H.A., Comans, R.N.J., 2006. The leaching of major and trace elements from MSWI bottom ash as a function of $\mathrm{pH}$ and time. Appl. Geochemistry 21, 
335-351. doi:10.1016/j.apgeochem.2005.11.003

Eurostat - European Statistical Office, 2018. Waste Electrical and Electronic Equipment
(WEEE) [WWW Document].

Gómez-Ariza, J.L., Giráldez, I., Sánchez-Rodas, D., Morales, E., 1999. Metal readsorption and redistribution during the analytical fractionation of trace elements in oxic estuarine sediments. Anal. Chim. Acta 399, 295-307. doi:10.1016/S0003-2670(99)00460-2

Gonzalez, M.L., Blanc, D., de Brauer, C., 2017. Multi-Analytical Approach and Geochemical Modeling for Mineral Trace Element Speciation in MSWI Bottom-Ash. Waste and Biomass Valorization 0, 0. doi:10.1007/s12649-017-0075-y

Hu, Y., Bakker, M.C.M., de Heij, P.G., 2011. Recovery and distribution of incinerated aluminum packaging waste. Waste Manag. 31, 2422-2430.

Hursthouse, A.S., 2001. The relevance of speciation in the remediation of soils and sediments contaminated by metallic elements - An overview and examples from Central Scotland, UK. J. Environ. Monit. 3, 49-60. doi:10.1039/b006132h

Izquierdo, M., López-Soler, A., Ramonich, E. V, Barra, M., Querol, X., 2002. Characterisation of bottom ash from municipal solid waste incineration in Catalonia. J. Chem. Technol. Biotechnol. 77, 576-583.

Jung, C.H., Matsuto, T., Tanaka, N., Okada, T., 2004. Metal distribution in incineration residues of municipal solid waste (MSW) in Japan. Waste Manag. 24, 381-391. doi:10.1016/S0956-053X(03)00137-5

Kaya, M., 2016. Recovery of metals and nonmetals from electronic waste by physical and chemical recycling processes. Waste Manag. 57, 64-90. doi:10.1016/j.wasman.2016.08.004 
Li, K., Xu, Z., 2015. Application of Supercritical Water To Decompose Brominated Epoxy Resin and Environmental Friendly Recovery of Metals from Waste Memory Module. Environ. Sci. Technol. 49, 1761-1767. doi:10.1021/es504644b

Loginova, E., Volkov, D.S., van de Wouw, P.M.F., Florea, M.V.A., Brouwers, H.J.H., 2019. Detailed characterization of particle size fractions of municipal solid waste incineration bottom ash. J. Clean. Prod. 207, 866-874.

doi:https://doi.org/10.1016/j.jclepro.2018.10.022

Morf, L.S., Gloor, R., Haag, O., Haupt, M., Skutan, S., Lorenzo, F. Di, Böni, D., 2013. Precious metals and rare earth elements in municipal solid waste - Sources and fate in a Swiss incineration plant. Waste Manag. 33, 634-644. doi:10.1016/j.wasman.2012.09.010

Puma, S., Marchese, F., Dominijanni, A., Manassero, M., 2013. Reuse of MSWI bottom ash mixed with natural sodium bentonite as landfill cover material. Waste Manag. Res. 31, $577-584$.

Rauret, G., López-Sánchez, J.F., Sahuquillo, A., Rubio, R., Davidson, C., Ure, A., Quevauviller, P., 1999. Improvement of the BCR three step sequential extraction procedure prior to the certification of new sediment and soil reference materials. J. Environ. Monit. 1, 57-61. doi:10.1039/a807854h

Schluep, M., Hagelueken, C., Kuehr, R., Magalini, F., Maurer, C., Meskers, C., Mueller, E., Wang, F., 2009. Recycling - from e-waste to resources. Berlin.

Wielgosiński, G., Wasiak, D., Zawadzka, A., 2014. The Use of Sequential Extraction for Assessing Environmental Risks of Waste Incineration Bottom Ash/Wykorzystanie Ekstrakcji Sekwencyjnej Do Oceny Zagrożeń Dla Środowiska Powodowanych Przez Żużle I Popioły Z. Ecol. Chem. Eng. S. doi:10.2478/eces-2014-0030 
Xia, Y., He, P., Shao, L., Zhang, H., 2017. Metal distribution characteristic of MSWI bottom ash in view of metal recovery. J. Environ. Sci. (China) 52, 178-189. doi:10.1016/j.jes.2016.04.016

Yao, J., Li, W.-B., Kong, Q.-N., Wu, Y.-Y., He, R., Shen, D.-S., 2010. Content, mobility and transfer behavior of heavy metals in MSWI bottom ash in Zhejiang province, China. Fuel 89, 616-622. doi:10.1016/J.FUEL.2009.06.016

Zhang, H., He, P.-J., Shao, L.-M., 2008. Fate of heavy metals during municipal solid waste incineration in Shanghai. J. Hazard. Mater. 156, 365-373. doi:10.1016/j.jhazmat.2007.12.025

Zhang, L., Xu, Z., 2016. A review of current progress of recycling technologies for metals from waste electrical and electronic equipment. J. Clean. Prod. 127, 19-36. doi:10.1016/J.JCLEPRO.2016.04.004

Zhang, Y., Li, Q., Jia, J., Meng, A., 2012. Thermodynamic analysis on heavy metals partitioning impacted by moisture during the MSW incineration. Waste Manag. 32, 2278-2286. doi:10.1016/J.WASMAN.2012.07.007

Zhou, B., Yang, Y., Reuter, M.A., Boin, U.M.J., 2006. Modelling of aluminium scrap melting in a rotary furnace. Miner. Eng. 19, 299-308. 
Table 1. Average of major component of seasonal WBA samples according to particle size, analysed by means XRF. Values reported in \% (wt/wt) with relative standard deviation.

\section{Particle Size Fraction (mm)}

\begin{tabular}{ccccccc}
\hline Component & Entire & $>\mathbf{1 6}$ & $\mathbf{1 6 - 8}$ & $\mathbf{8}$ - 4 & $\mathbf{4 - 2}$ & $\mathbf{2 ~ - ~ 0 ~}$ \\
\hline $\mathbf{S i O}_{\mathbf{2}}$ & $42.01 \pm 6.14$ & $51.08 \pm 4.82$ & $54.00 \pm 7,77$ & $53.74 \pm 4.44$ & $43.73 \pm 3.58$ & $25.32 \pm 3.14$ \\
$\mathbf{C a O}$ & $26.55 \pm 7.57$ & $14.84 \pm 7.16$ & $15.26 \pm 2.60$ & $16.84 \pm 2.21$ & $20.99 \pm 5.39$ & $25.94 \pm 4.05$ \\
$\mathbf{A l}_{\mathbf{2}} \mathbf{O}_{\mathbf{3}}$ & $8.07 \pm 2.57$ & $8.93 \pm 3.54$ & $5.43 \pm 0.62$ & $5.48 \pm 0.20$ & $8.23 \pm 2.15$ & $9.64 \pm 2.81$ \\
$\mathbf{N a}_{\mathbf{2}} \mathbf{O}$ & $4.62 \pm 1.19$ & $3.44 \pm 0.96$ & $6.24 \pm 1.94$ & $6.46 \pm 1.81$ & $4.75 \pm 1.77$ & $2.36 \pm 1.17$ \\
$\mathbf{F e}_{\mathbf{2}} \mathbf{O}_{\mathbf{3}}$ & $4.80 \pm 0.20$ & $2.67 \pm 0.75$ & $4.94 \pm 1.09$ & $3.72 \pm 0.13$ & $4.75 \pm 1.10$ & $5.09 \pm 1,69$ \\
$\mathbf{M g O}$ & $3.37 \pm 0.28$ & $1.97 \pm 0.72$ & $2.01 \pm 0.06$ & $1.58 \pm 0.23$ & $2.85 \pm 0.29$ & $2.75 \pm 0.16$ \\
$\mathbf{S O}_{\mathbf{3}}$ & $2.51 \pm 0.21$ & $1.91 \pm 0.33$ & $0.52 \pm 0.04$ & $0.89 \pm 0.09$ & $1.51 \pm 0.08$ & $2.97 \pm 0.76$ \\
$\mathbf{K}_{\mathbf{2}} \mathbf{O}$ & $1.86 \pm 0.13$ & $1.96 \pm 0.27$ & $1.40 \pm 0.38$ & $1.25 \pm 0.08$ & $1.56 \pm 0.37$ & $1.32 \pm 0.37$ \\
$\mathbf{P}_{\mathbf{2}} \mathbf{O}_{\mathbf{5}}$ & $1.56 \pm 0.45$ & $0.36 \pm 0.05$ & $0.43 \pm 0.08$ & $0.89 \pm 0.19$ & $1.60 \pm 0.28$ & $2.02 \pm 0.1$ \\
$\mathbf{T i O}_{\mathbf{2}}$ & $0.81 \pm 0.31$ & $0.58 \pm 0.13$ & $0.37 \pm 0.15$ & $0.49 \pm 0.13$ & $0.69 \pm 0.23$ & $0.93 \pm 0.21$ \\
$\mathbf{M n O}$ & $0.08 \pm 0.02$ & $0.04 \pm 0.01$ & $0.07 \pm 0.01$ & $0.06 \pm 0.02$ & $0.09 \pm 0.02$ & $0.11 \pm 0.03$ \\
\hline
\end{tabular}


Table 2. Total acid digestion data for of WBA seasonal samples. Values reported in $\mathrm{mg} \cdot \mathrm{kg}^{-1}$ with standard deviation.

\begin{tabular}{|c|c|c|c|c|c|c|c|c|c|c|c|c|c|c|}
\hline \multirow[b]{2}{*}{$(\mathbf{m m})$} & \multicolumn{14}{|c|}{ WBA collected on February } \\
\hline & Ag & Al & Au & Be & Co & $\mathbf{C u}$ & Ga & In & $\mathbf{L i}$ & $\mathbf{N i}$ & Pd & $\mathbf{S b}$ & Ta & $\mathbf{W}$ \\
\hline$>16$ & $1.32 \pm 0.78$ & $56682 \pm 752$ & $0.325 \pm 0.181$ & $5.25 \pm 0.21$ & $11.5 \pm 0.0$ & $81.1 \pm 1.2$ & $15.4 \pm 0.0$ & $0.030 \pm 0.007$ & $34.8 \pm 0.2$ & $26.5 \pm 0.5$ & $1.51 \pm 0.02$ & $18.5 \pm 0.3$ & $0.590 \pm 0.344$ & $4.38 \pm 0.10$ \\
\hline $16-8$ & $1.38 \pm 0.02$ & $58789 \pm 4804$ & $0.330 \pm 0.154$ & $1.61 \pm 0.27$ & $8.81 \pm 0.25$ & $2837 \pm 222$ & $8.07 \pm 0.35$ & $0.055 \pm 0.025$ & $29.2 \pm 0.4$ & $62.2 \pm 6.7$ & $0.595 \pm 0.022$ & $46.6 \pm 1.6$ & $0.610 \pm 0.402$ & $1.56 \pm 0.09$ \\
\hline $8-4$ & $2.83 \pm 0.33$ & $62562 \pm 3164$ & $0.325 \pm 0.202$ & $1.04 \pm 0.48$ & $9.81 \pm 0.65$ & $1359 \pm 55$ & $7.84 \pm 0.37$ & $0.050 \pm 0.032$ & $33.7 \pm 1.0$ & $38.1 \pm 6.0$ & $0.927 \pm 0.118$ & $64.9 \pm 4.2$ & $0.660 \pm 0.350$ & $1.69 \pm 0.86$ \\
\hline $4-2$ & $3.50 \pm 0.61$ & $89414 \pm 4989$ & $0.320 \pm 0.180$ & $0.730 \pm 0.193$ & $15.6 \pm 2.0$ & $4092 \pm 512$ & $11.8 \pm 0.2$ & $0.055 \pm 0.030$ & $39.6 \pm 1.4$ & $71.5 \pm 9.1$ & $0.985 \pm 0.076$ & $41.2 \pm 2.8$ & $0.535 \pm 0.434$ & $2.23 \pm 0.52$ \\
\hline $2-0$ & $3.45 \pm 0.35$ & $58301 \pm 559$ & $0.803 \pm 0.319$ & $1.20 \pm 0.21$ & $32.7 \pm 0.9$ & $2074 \pm 59$ & $10.9 \pm 0.1$ & $0.065 \pm 0.023$ & $26.9 \pm 0.6$ & $109 \pm 11$ & $0.917 \pm 0.062$ & $45.6 \pm 4.3$ & $0.750 \pm 0.283$ & $4.58 \pm 0.23$ \\
\hline \multirow[t]{2}{*}{ Entire } & $2.44 \pm 1.44$ & $64038 \pm 3465$ & $0.420 \pm 0.231$ & $1.02 \pm 0.23$ & $12.4 \pm 0.7$ & $2498 \pm 86$ & $10.8 \pm 0.3$ & $0.055 \pm 0.019$ & $32.6 \pm 0.4$ & $88.0 \pm 4.6$ & $0.991 \pm 0.053$ & $26.1 \pm 1.3$ & $0.590 \pm 0.361$ & $1.73 \pm 0.14$ \\
\hline & \multicolumn{14}{|c|}{ WBA collected on July } \\
\hline$(\mathbf{m m})$ & Ag & Al & Au & Be & Co & $\mathrm{Cu}$ & Ga & In & $\mathbf{L i}$ & $\mathbf{N i}$ & Pd & $\mathbf{S b}$ & Ta & $\mathbf{W}$ \\
\hline$>16$ & $2.64 \pm 0.39$ & $49340 \pm 363$ & $1.00 \pm 0.22$ & $1.24 \pm 0.28$ & $21.5 \pm 0.6$ & $446 \pm 11$ & $13.7 \pm 0.1$ & $0.083 \pm 0.008$ & $36.6 \pm 0.7$ & $38.2 \pm 1.5$ & $0.992 \pm 0.021$ & $50.3 \pm 1.0$ & $0.705 \pm 0.361$ & $2.60 \pm 0.17$ \\
\hline $16-8$ & $3.88 \pm 1.52$ & $69717 \pm 216$ & $1.25 \pm 0.45$ & $1.50 \pm 0.42$ & $9.04 \pm 0.67$ & $612 \pm 219$ & $11.3 \pm 0.5$ & $0.053 \pm 0.014$ & $36.4 \pm 3.6$ & $26.9 \pm 4.6$ & $0.904 \pm 0.073$ & $20.0 \pm 0.8$ & $0.935 \pm 0.442$ & $2.31 \pm 0.38$ \\
\hline $8-4$ & $2.74 \pm 0.66$ & $67798 \pm 3272$ & $0.925 \pm 0.434$ & $2.02 \pm 0.33$ & $252 \pm 52$ & $1721 \pm 57$ & $7.93 \pm 0.30$ & $0.055 \pm 0.010$ & $59.9 \pm 3.1$ & $109 \pm 10$ & $0.811 \pm 0.043$ & $41.6 \pm 1.4$ & $0.745 \pm 0.381$ & $2.65 \pm 0.24$ \\
\hline $4-2$ & $2.30 \pm 0.25$ & $42470 \pm 7732$ & $0.775 \pm 0.242$ & $1.05 \pm 0.21$ & $18.0 \pm 5.4$ & $2323 \pm 79$ & $12.6 \pm 2.9$ & $0.054 \pm 0.020$ & $42.5 \pm 0.7$ & $145 \pm 51$ & $1.21 \pm 0.06$ & $57.8 \pm 1.8$ & $0.820 \pm 0.674$ & $4.01 \pm 1.19$ \\
\hline $2-0$ & $4.18 \pm 0.26$ & $54165 \pm 2791$ & $0.770 \pm 0.152$ & $0.835 \pm 0.103$ & $36.1 \pm 3.1$ & $2996 \pm 304$ & $10.8 \pm 0.4$ & $0.096 \pm 0.021$ & $38.0 \pm 1.6$ & $159 \pm 16$ & $1.03 \pm 0.06$ & $73.1 \pm 2.3$ & $0.990 \pm 0.630$ & $5.45 \pm 0.29$ \\
\hline \multirow[t]{2}{*}{ Entire } & $5.90 \pm 0.35$ & $76605 \pm 12242$ & $1.44 \pm 0.19$ & $0.565 \pm 0.170$ & $65.5 \pm 6.1$ & $2122 \pm 530$ & $10.9 \pm 0.1$ & $0.268 \pm 0.123$ & $30.2 \pm 0.7$ & $140 \pm 36$ & $1.06 \pm 0.10$ & $47.7 \pm 4.3$ & $0.720 \pm 0.431$ & $3.78 \pm 0.43$ \\
\hline & \multicolumn{14}{|c|}{ WBA collected on October } \\
\hline$(\mathbf{m m})$ & Ag & Al & $\mathbf{A u}$ & Be & Co & $\mathbf{C u}$ & Ga & In & $\mathbf{L i}$ & $\mathbf{N i}$ & Pd & Sb & Ta & $\mathbf{W}$ \\
\hline$>16$ & $1.34 \pm 0.10$ & $51474 \pm 288$ & $1.24 \pm 0.05$ & $1.39 \pm 0.12$ & $33.5 \pm 1.5$ & $381 \pm 9$ & $12.5 \pm 0.4$ & $0.070 \pm 0.009$ & $29.1 \pm 0.5$ & $61.4 \pm 3.7$ & $0.834 \pm 0.067$ & $11.0 \pm 0.9$ & $1.27 \pm 0.09$ & $3.51 \pm 0.74$ \\
\hline $16-8$ & $2.09 \pm 0.18$ & $43626 \pm 311$ & $0.490 \pm 0.087$ & $1.28 \pm 0.18$ & $10.3 \pm 0.3$ & $364 \pm 26$ & $8.82 \pm 0.24$ & $0.052 \pm 0.006$ & $144 \pm 1$ & $35.3 \pm 2.5$ & $0.679 \pm 0.012$ & $108 \pm 1$ & $0.85 \pm 0.09$ & $2.31 \pm 0.04$ \\
\hline $8-4$ & $2.28 \pm 0.21$ & $36747 \pm 3081$ & $0.440 \pm 0.021$ & $1.31 \pm 0.05$ & $12.4 \pm 0.6$ & $840 \pm 18$ & $6.90 \pm 0.29$ & $0.030 \pm 0.001$ & $35.1 \pm 0.3$ & $48.9 \pm 10.7$ & $0.802 \pm 0.031$ & $38.8 \pm 0.7$ & $0.72 \pm 0.07$ & $3.09 \pm 0.12$ \\
\hline $4-2$ & $16.6 \pm 9.9$ & $57746 \pm 8072$ & $1.07 \pm 0.12$ & $1.55 \pm 0.27$ & $17.4 \pm 3.6$ & $2410 \pm 262$ & $10.6 \pm 1.2$ & $0.100 \pm 0.012$ & $35.7 \pm 0.4$ & $125 \pm 22$ & $0.796 \pm 0.072$ & $62.3 \pm 9.5$ & $1.63 \pm 0.07$ & $4.19 \pm 0.53$ \\
\hline $2-0$ & $5.68 \pm 1.96$ & $59494 \pm 301$ & $1.40 \pm 0.09$ & $1.25 \pm 0.02$ & $38.6 \pm 2.2$ & $2708 \pm 141$ & $9.00 \pm 1.11$ & $0.160 \pm 0.017$ & $26.8 \pm 5.0$ & $133 \pm 9$ & $0.730 \pm 0.098$ & $52.7 \pm 46.5$ & $5.60 \pm 4.90$ & $5.08 \pm 3.74$ \\
\hline Entire & $3.30 \pm 1.00$ & $56389 \pm 1801$ & $1.44 \pm 0.13$ & $1.84 \pm 0.17$ & $22.3 \pm 4.5$ & $2008 \pm 40$ & $9.85 \pm 0.52$ & $0.060 \pm 0.004$ & $31.5 \pm 1.6$ & $298 \pm 16$ & $0.808 \pm 0.130$ & $40.5 \pm 3.0$ & $1.49 \pm 0.11$ & $14.90 \pm 0.7$ \\
\hline
\end{tabular}


Table 3. Major crystallographic phases identified by XRD from the initial (Entire) WBA sample collected on July and from the Residue fractions generated in each step of the SEP.

\begin{tabular}{|c|c|c|c|c|}
\hline Initial phases in WBA & Residue 1 & Residue 2 & Residue 3 & Residue 4 \\
\hline Calcium Silicate Hydroxide & $\bar{\checkmark}$ & $\bar{\checkmark}$ & $\bar{\checkmark}$ & $\sqrt{ }^{*}$ \\
\hline Quartz & $\checkmark$ & $\checkmark$ & $\checkmark$ & $\checkmark$ \\
\hline Gehlenite & $\checkmark$ & $\checkmark$ & $x^{* * *}$ & $x$ \\
\hline Hydroxylapatite & $\checkmark$ & $\checkmark$ & $\checkmark$ & $x$ \\
\hline Hydrocalumine & $x$ & $x$ & $x$ & $x$ \\
\hline Calcium Aluminum Chloride Hydroxide Hydrate & $x$ & $x$ & $x$ & $x$ \\
\hline Calcite & $\checkmark$ & $\checkmark^{*}$ & $x^{* * *}$ & $x$ \\
\hline Anhydrite & $x$ & $x$ & $x$ & $x$ \\
\hline Sodium Calcium Aluminum Silicate & $\checkmark$ & $\checkmark$ & $\checkmark$ & $\checkmark^{*}$ \\
\hline Potassium-Feldspar & $\checkmark$ & $\checkmark$ & $x^{* * *}$ & $x$ \\
\hline Orthoferrosilite & $\checkmark$ & $\checkmark$ & $\checkmark$ & $\checkmark$ \\
\hline Hematite & $\checkmark$ & $\checkmark$ & $\checkmark$ & $\checkmark$ \\
\hline Calcium Silicate & $\checkmark$ & $\checkmark$ & $x^{* * *}$ & $x$ \\
\hline Ammonium Chloride & -- & --- & $\checkmark^{* *}$ & $x$ \\
\hline $\begin{array}{l}* \text { decreasing of peak } \\
\text { ** coming from the ex } \\
\text { *** dissolved complete } \\
\text { not for its reducin }\end{array}$ & $\begin{array}{l}\text { ntensity } \\
\text { action reagent } \\
\text { because of the } \\
\text { roperties }\end{array}$ & $\begin{array}{l}\text { ed } \\
\text { Hof the reage }\end{array}$ & & \\
\hline
\end{tabular}


Table 4. Chemical characterization determined by XRF from the Residue fractions generated in each step of the SEP. Values reported in \% (wt/wt).

\begin{tabular}{|c|c|c|c|c|}
\hline & Residue 1 & Residue 2 & Residue 3 & Residue 4 \\
\hline $\mathrm{SiO}_{2}$ & 34,00 & 46,15 & 44,35 & 54,95 \\
\hline $\mathrm{CaO}$ & 37,55 & 23,50 & 14,95 & 9,44 \\
\hline $\mathrm{Fe}_{2} \mathrm{O}_{3}$ & 6,23 & 7,64 & 8,26 & 11,95 \\
\hline $\mathrm{Al}_{2} \mathbf{O}_{3}$ & 4,60 & 6,97 & 4,76 & 5,69 \\
\hline MgO & 2,29 & 2,40 & 1,61 & 1,32 \\
\hline $\mathrm{SO}_{3}$ & 2,00 & 0,45 & 0,38 & 0,17 \\
\hline $\mathbf{P}_{2} \mathbf{O}_{5}$ & 1,97 & 2,71 & 2,87 & 1,64 \\
\hline $\mathrm{K}_{2} \mathrm{O}$ & 1,70 & 1,83 & 1,99 & 2,28 \\
\hline $\mathrm{TiO}_{2}$ & 1,62 & 1,92 & 2,39 & 3,16 \\
\hline $\mathrm{Cl}$ & 0,45 & 0,31 & 12,90 & 2,27 \\
\hline $\mathrm{SiO}_{2} / \mathrm{Al}_{2} \mathrm{O}_{3}$ & 7,40 & 6,63 & 9,32 & 9,67 \\
\hline $\mathrm{SiO}_{2} / \mathrm{CaO}$ & 0,91 & 1,96 & 2,97 & 5,82 \\
\hline $\mathrm{Al}_{2} \mathrm{O}_{3} / \mathrm{CaO}$ & 0,12 & 0,30 & 0,32 & 0,60 \\
\hline $\mathrm{Fe}_{2} \mathrm{O}_{3} / \mathrm{CaO}$ & 0,17 & 0,32 & 0,55 & 1,27 \\
\hline
\end{tabular}




\section{Figure Caption}

Fig. 1. (a) Particle size distribution (PSD) of the seasonal weather bottom ash (WBA)

samples; (b) Average of metal content in each fraction of the seasonal WBA samples. Particle size fractions reported in $\mathrm{mm}$.

Fig 2. Partition and total content of valuable metals (In, Au, Pd, Ta, Be, Ag and W) extracted from WBA sample collected on July, in accordance with each step of the sequential extraction and total digestion procedures. Particle size fractions reported in $\mathrm{mm}$.

Fig 3. Partition and total content of valuable metals ( $\mathrm{Ga}, \mathrm{Li}, \mathrm{Sb}, \mathrm{Co}, \mathrm{Ni}, \mathrm{Cu}$ and $\mathrm{Al}$ ) extracted from WBA sample collected on July, in accordance with each step of the sequential extraction and total digestion procedures. Particle size fractions reported in $\mathrm{mm}$. 

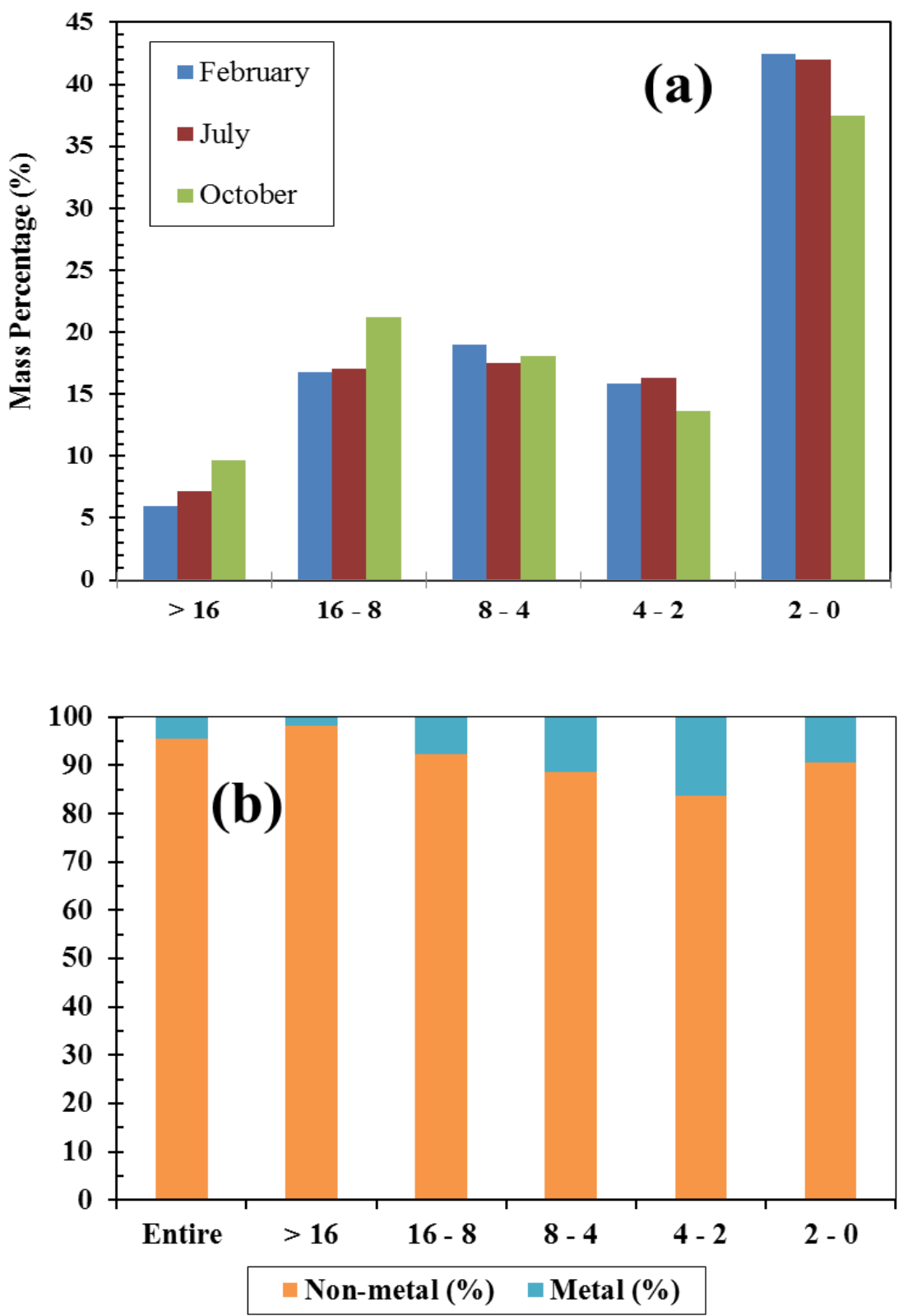

Fig. 1 

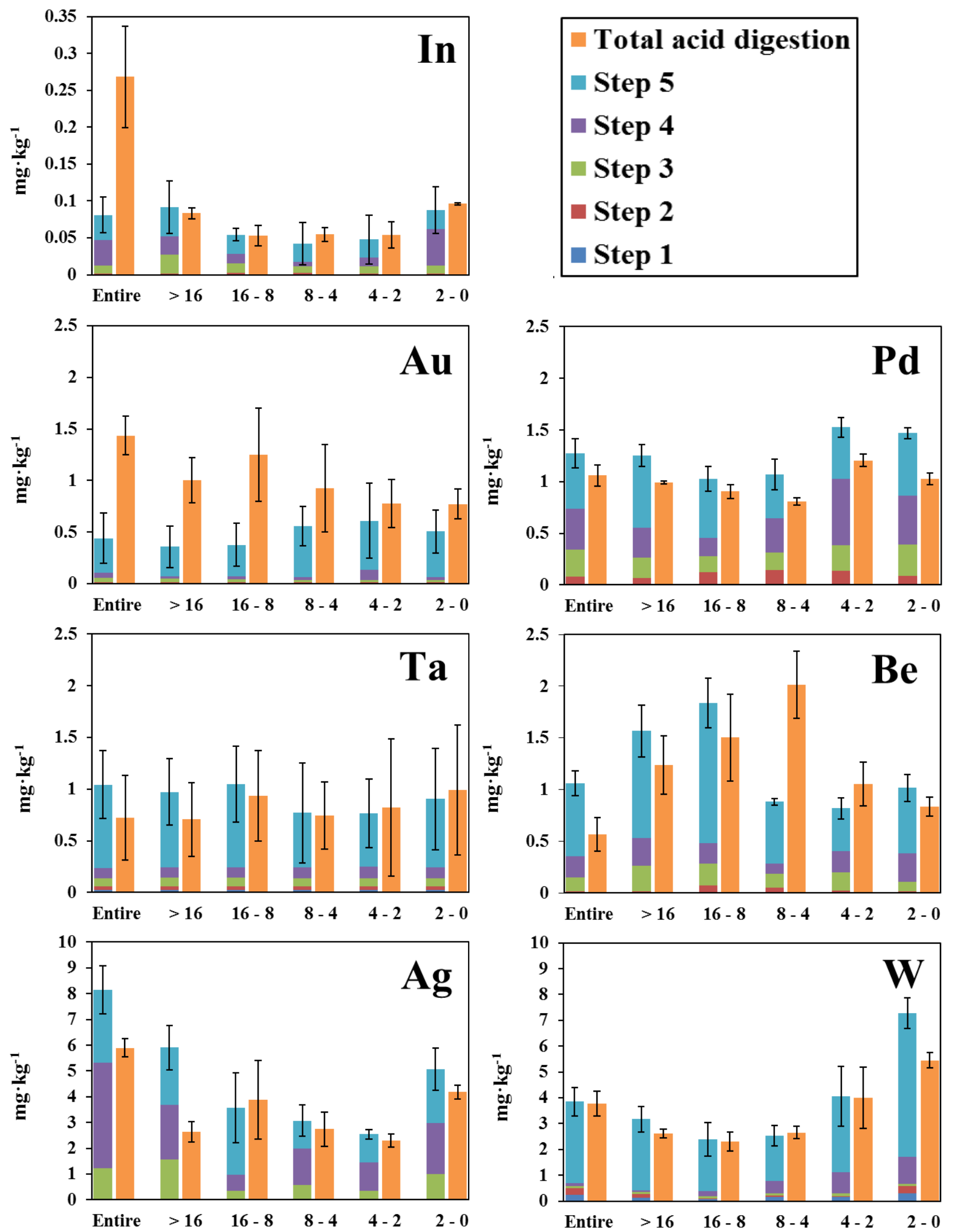

Fig 2.

\section{Total acid digestion}

Step 5

- Step 4

Step 3

- Step 2

Step 1

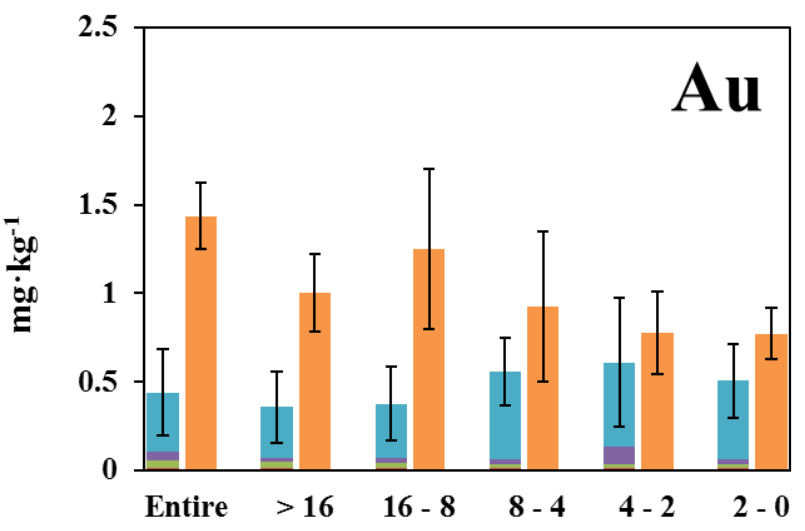




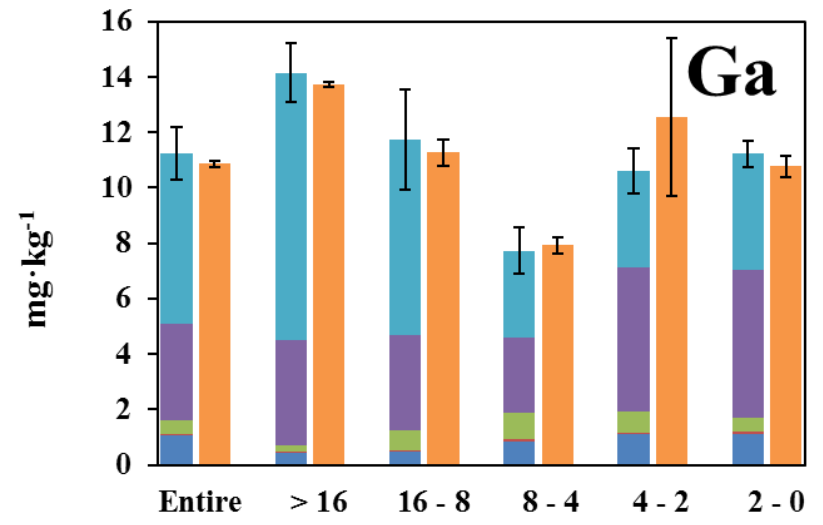

Total acid digestion

- Step 5

- Step 4

Step 3

- Step 2

Step 1
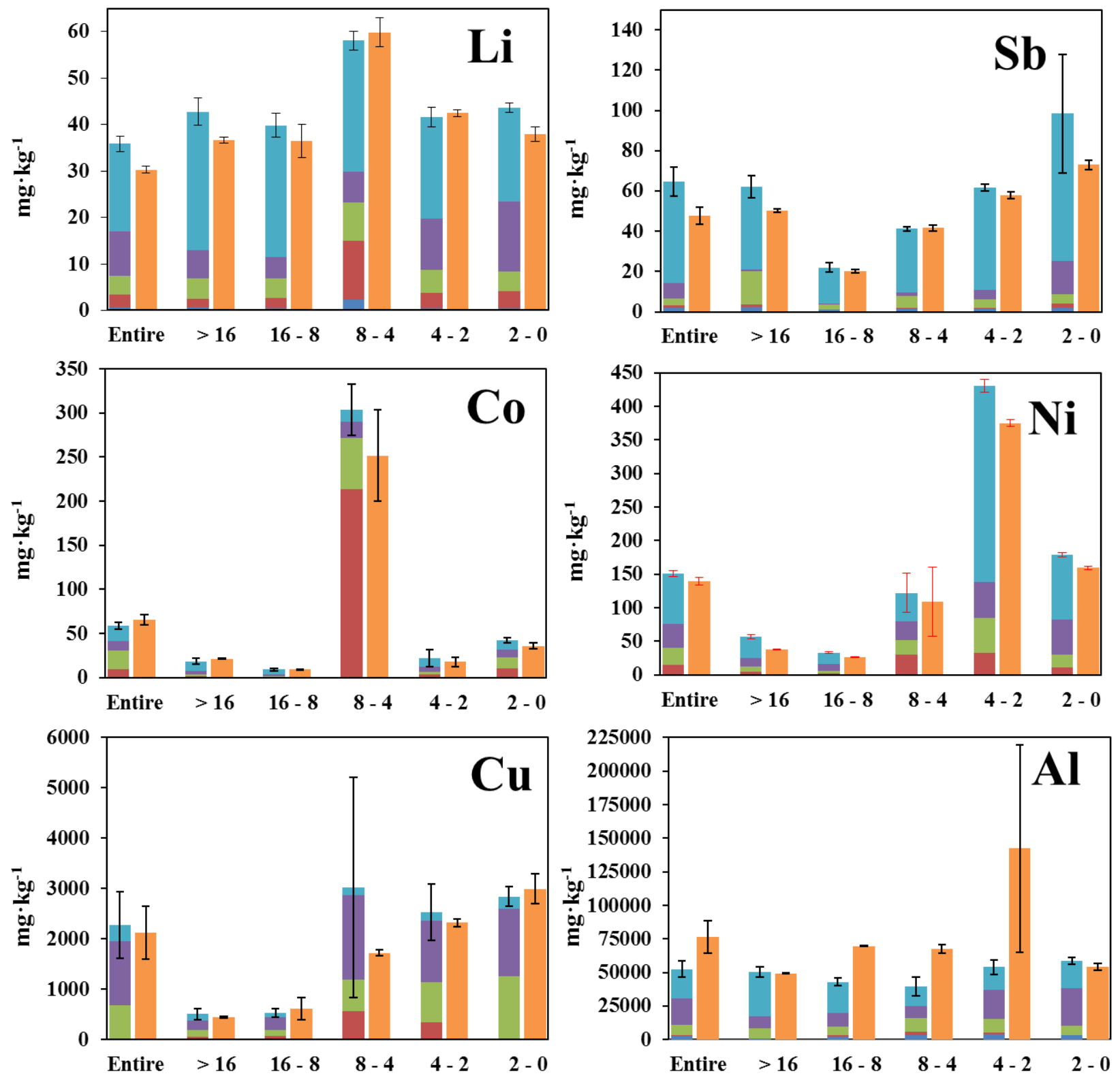

Fig. 3 